Addendum

\title{
Addendum: Willard, D.T. and Loferski, J.R. Skateboards as a Sustainable Recyclable Material. Recycling 2018, 3, 20
}

\section{Dylan T. Willard and Joseph R. Loferski *}

Department of Sustainable Biomaterials, Virginia Tech, Blacksburg, VA 24061, USA; dylanw3@vt.edu

* Correspondence: jloferski@vt.edu; Tel.: +1-540-231-4405; Fax: +1-540-231-8868

Received: 3 October 2018; Accepted: 24 October 2018; Published: 26 October 2018

The authors would like to add the following statement to the published article [1]. The Acknowledgements of the original paper would be updated to the following version:

"Acknowledgements: The authors would like to give photograph credit to Heather Arnold on Figures 5, 6, 7, 8, 13, 14, 15, 16, 17, 18, 19, and 20 in the paper".

The manuscript will be updated and the original will remain online on the article's webpage.

\section{References}

1. Willard, D.T.; Loferski, J.R. Skateboards as a Sustainable Recyclable Material. Recycling 2018, 3, 20. [CrossRef]

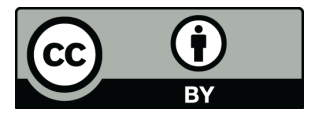

